\title{
San Pedro de Loarre als triadischer Schrift-, Bild- und Zeichenraum
}

Mit der Unterkirche der aragonesischen Burg von Loarre (Abb.1) ist der Sonderfall eines ,segmentierten' sakralen Schriftraums gegeben, ${ }^{1}$ der in ein Kirchenportal, das zugleich den Zugang zur Hauptburg darstellt, eine tonnengewölbte Treppe mit Inschrift an der Seite und eine liminale Situation am Übergang in die Unterkirche gegliedert ist. Alle drei Räume sind jedoch eng aufeinander abgestimmt und bilden eine Einheit. Dieser Sakralschriftraum von Loarre hat bislang in der Forschung kaum Beachtung gefunden, so dass selbst zwei außergewöhnliche figürliche Reliefs aus dieser Raumstaffelung noch unpubliziert sind. Dieser Sonderfall wird sodann mit dem mutmaßlichen Vorbild des ungleich bekannteren Schriftraums der zu Loarre nahegelegenen Bischofskirche von Jaca verglichen, um insbesondere die Unterschiede herauszuarbeiten. Abschließend folgt der Versuch, diese Innovationen in einen breiteren Kontext von Schrifträumen der Iberischen Halbinsel einzuordnen und eine Interpre-

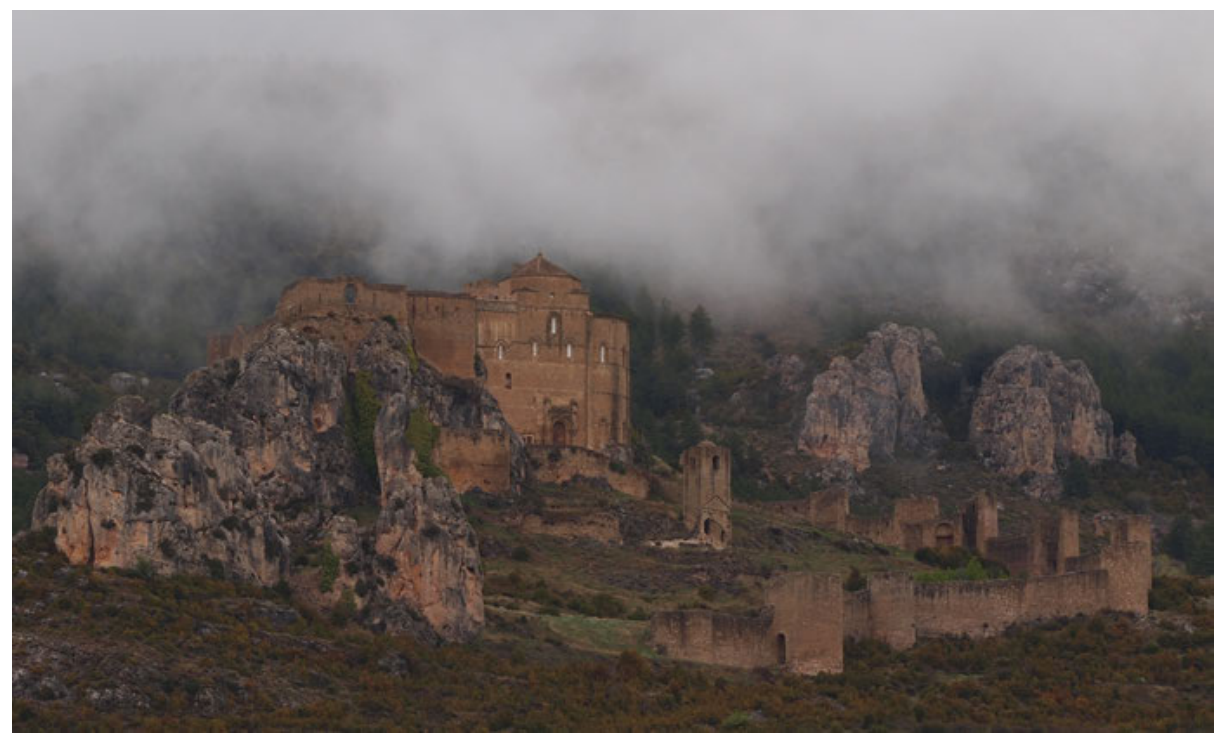

Abb.1: Loarre, Burg S. Pedro, Gesamtansicht von Süden.

1 Die Genese der vielschichtigen Austauschverhältnisse zwischen Schrift und Bild seit dem frühen Mittelalter zeichnet Diebold 2000 nach. Basale Überlegungen zu mit Bild und Schrift versehenen Räumen finden sich in Assmann 2012; Giersiepen/Kottje 1995 sowie bei allen Beiträgern des Heidelberger SFB 933 „Materiale Textkulturen“.

Ә Open Access. () 2019 Stefan Trinks, publiziert von De Gruyter. (c) BY-NC-ND Dieses Werk ist lizenziert unter der Creative Commons Attribution-NonCommercial-NoDerivatives 4.0 Lizenz. 
tation der miteinander eng vernetzten Bedeutungsschichten des sakralen Schriftraums von Loarre zu geben. Die These lautet dabei, dass Loarre auf bestimmten, im Folgenden vorzustellenden Innovationen von Bild-Schrifträumen aus der Kathedrale San Pedro de Jaca aufbaut, um die Triade Raum sowie die Bilder und die Schrift darin zusätzlich mit Zeichencharakter aufzuladen. Das chronologisch vorgängige Vorbild Jaca wird dadurch an Komplexität noch gesteigert.

\section{Loarre - Schrift-bildlich fixierte Heilserwartungen}

Mit der auf einem Felssporn auf $1071 \mathrm{~m}$ Höhe über dem damaligen Feindesland der weit einsehbaren Ebene Plana de Huesca thronenden Grenzburg von Loarre als einer der besterhaltenen Burgen des elften Jahrhunderts hat sich in den vergangenen Jahrzehnten vor allem die Burgenforschung intensiv beschäftigt. ${ }^{2}$ Für den HollywoodBlockbuster Kingdom of Heaven ${ }^{3}$ war sie die Vorausschau und Spiegelung für das im Kreuzzug zu befreiende irdische Jerusalem, in deren Schatten der Filmprotagonist Orlando Bloom metaphorisch seine Waffen für die Verteidigung der Stadt gegen Sultan Saladin schmiedete. Neben der unleugbaren Tauglichkeit als Idealkulisse von Burg ist daran wahr, dass sich tatsächlich ein Teil der Burgbesatzung nicht nur an der Rückeroberung der Iberischen Halbinsel von den Arabern beteiligte, sondern auch an der Befreiung des Heiligen Landes von diesen. ${ }^{4}$

König Sancho Ramírez von Aragón ließ die Anlage in ihren wesentlichen Teilen in den Jahren 1071 bis 1095 errichten. In der Zeit des Hochmittelalters hatte die Burg von Loarre gegenüber der unweiten maurischen Stellung von Bolea in der Ebene eine grundlegende strategische Bedeutung im Verteidigungssystem von Aragón, um das handelswichtige Ebrotal freizukämpfen. Als mächtigste Festungsanlage in einem Ring aus insgesamt sieben Burgen nahm sie eine Schlüsselstellung bei der christlichen Wiedereroberung Aragóns, der Reconquista, ${ }^{5}$ im elften und zwölften Jahrhundert ein, weshalb die kanadische Forscherin Janice Mann im Jahr 2009 ihrer grundlegenden Arbeit zur romanischen Architektur und speziell auch zu Loarre zu Recht den Untertitel Exploring Frontiers and Defining Identities gab. ${ }^{6}$

Die Burgkirche San Pedro de Loarre, deren Oberkirche aufgesockelt über einer Unterkirche die ohnehin schon mächtige Burganlage noch überragt (Abb.2), hat bei Kunsthistorikern Beachtung aufgrund ihrer offensichtlichen stilistischen Nähe als

2 Siehe z. B. von deutscher Seite aus Großmann 2005, 96 oder Leonardy/Kersten 2002, 54-56 und von spanischer Guitart Aparicio 2004 oder Poza Yagüe 2009, 51-81.

3 Kingdom of Heaven (dt. Königreich der Himmel) US/GB/ES/DE/MA 2005, R: Ridley Scott.

4 Zur spanischen Beteiligung an den Kreuzzügen im Heiligen Land vgl. v. a. Jaspert 2014 und 2015.

5 Hierzu v. a. Bronisch 1998 und Poza Yagüe 2009, v. a. 80-81.

6 Mann 2009, v. a. 115-116. 


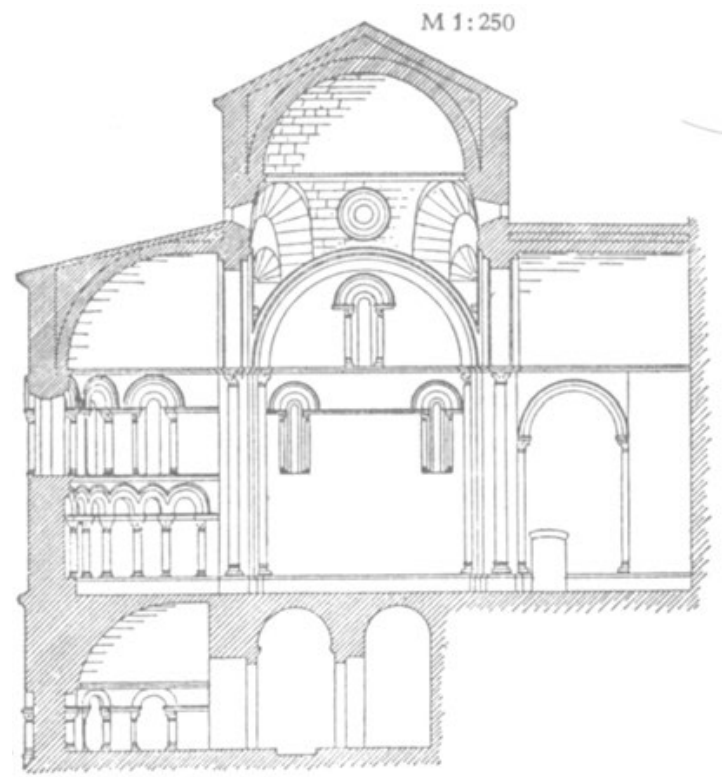

Abb. 2: Loarre, Querschnitt: Oberkirche auf Unterkirche.

Folgeauftrag der berühmten, 1076 gegründeten und damit am Anfang der romanischen monumentalfigürlichen Kapitellskulptur stehenden Stiftung desselben Königs Sancho Ramírez, San Pedro de Jaca, gefunden. ${ }^{7}$ So gut wie nie aber wurde die buchstäblich das Fundament für diese Burgkirche San Pedro de Loarre bildende kryptaartige ,Unterkirche' mit ihrem eigenen Patrozinium Santa Quiteria beachtet, obwohl diese in mehrfacher Hinsicht einen interessanten Sonderfall innerhalb der spanischen sakralen Schrifträume darstellt.

Doch nähern wir uns diesen Schrift-Bildräumen sukzessive: Selbst aus kilometerweiter Entfernung ist das vorspringende Blockportal nach dem Vorbild antiker Triumphbögen (Abb.3) als dunkle Öffnung in der mächtigen Schauwand der Burgkirche zu sehen, da es nie von einer Wehrmauer verdeckt war. ${ }^{8}$ Die Burg kann nur durch diesen Eingang betreten werden. Über dem Rundbogenportal befindet sich ein heute stark durch einen brachialen Dacheinbau des 18. Jahrhunderts zerstörter Relieffries, wie eine Zeichnung vor dem Umbau zeigt (Abb.4). ${ }^{9}$ Im Zentrum des oben gerade abschließenden Frieses ist die Hälfte eines in der Mandorla thronenden Parusie-Christus zu erkennen, flankiert von zwei monumentalen Erzengeln mit Schriftbändern; das Philaktet des linken Engels ist noch zu entziffern als GAB/RIE/L-

7 Trinks 2012, z. B. 239-240 und 310-311. Dort auch die umfängliche Literatur zum Thema.

8 Seehausen 2017, 220.

9 Español Bertran 2005-2006, 9. Die erstaunlich genaue Zeichnung aus dem Jahr 1637 im Codex Valentinus ms. 3610 des Conde de Guimerá in der Madrider Biblioteca Nacional, hält auf Folio 197r das zu diesem Zeitpunkt noch vollständig erhaltene Portal fest und benennt durch Beischriften die Ikonographie der Skulpturen. 


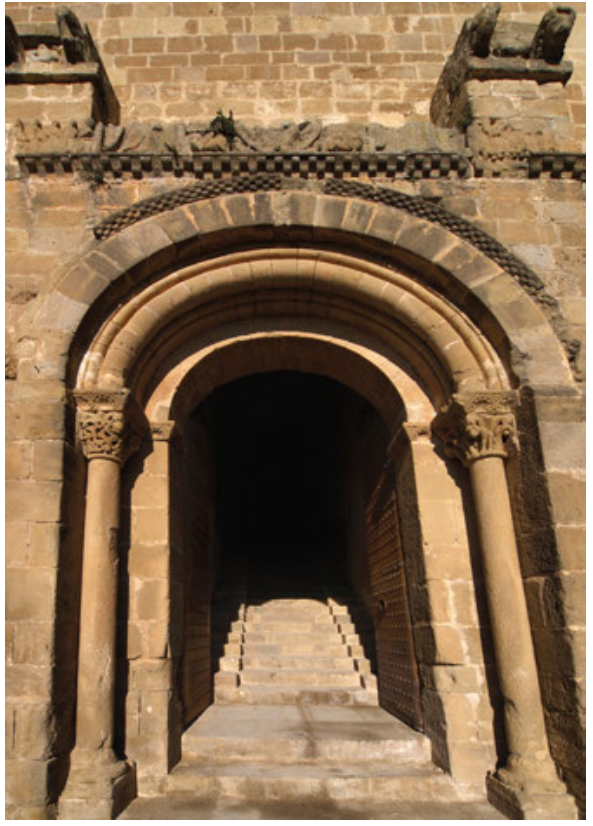

Abb. 3: Loarre, Portal.

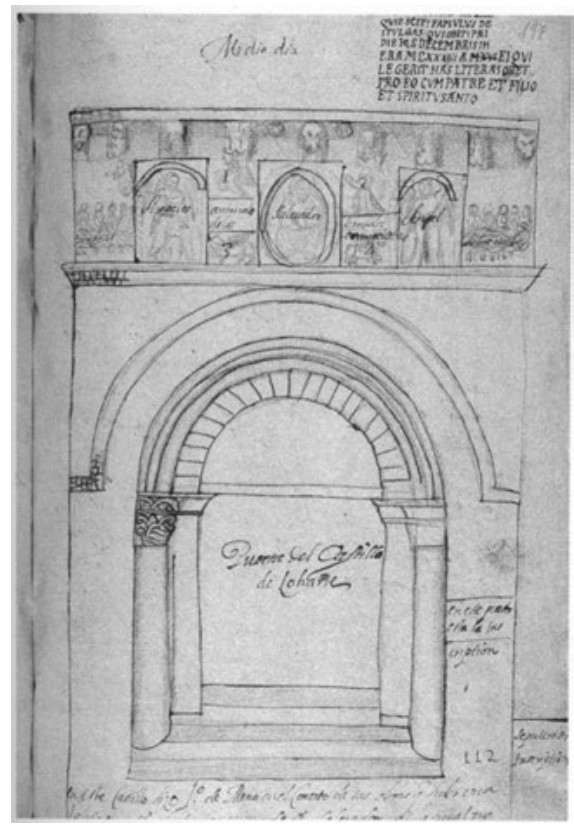

Abb. 4: Loarre, Portal, Alter Zustand 18. Jahrhundert.

FO/RTI/TU/DO/DEI, das des anderen ausgewittert und unleserlich. Damit wird hier dem Verkündigungsengel Gabriel nach dem Bibelwort in Offenbarung 7,12 - im Rahmen einer Grenzfestung konsequent - inschriftlich die Stärke im Kampf für Gott und gegen potentielle Angreifer der Burg zugeordnet. ${ }^{10}$ Dieses fast apotropäische Zeigen von Stärke findet sich ebenfalls über dem Portal in einer weiteren Inschrift, die nur wenige Jahrzehnte nach dessen Erbauung, aber offenbar bereits nach Abzug und Verlegung der arabischen Truppen stolz verkündete: Schütze diese unbesiegten Mauern - 1103, AEDES HAS MUNIAS INVICTAS - MCIII. ${ }^{11}$ Auf dem Relief zur Rechten Christi, in der christlichen Ikonographie der Ort der Seligen, reihen sich Menschen hinter Tüchern, die sie aufspannen, offensichtlich die Szene der in reinweiße Tücher eingekleideten Auserwählten beim Weltgericht nach Offenbarung 6,11 und damit eine Verheißung des Paradieses. ${ }^{12}$ Überraschenderweise findet sich aber auch auf der gegenüberliegenden Friesseite noch im ursprünglich Bauzusammenhang, wie ein Vergleich mit der Zeichnung des 17. Jahrhunderts erweist, eine nahezu identische Darstellung ohne abwertende Attribute. Somit liegt hier neben dem späteren Pórtico de la Gloria-Haupttympanon in Santiago von 1188 der so weit zu sehen

10 Español Bertran 2005-2006, 15 und stärker noch Poza Yagüe 2009, 73.

11 Leonardy/Kersten 2002, 56.

12 Trinks 2010, 15-16. 
einzige Fall vor, in dem keine Verdammten, sondern ausschließlich Selige bei der Parusie zugegen sind. ${ }^{13}$ Möglicherweise war diese vorgezogene Paradiesesgewissheit ein polemisches Zeichen in Richtung der nur wenige Kilometer entfernt in der Ebene stationierten Araber, denn das Hauptportal der Burg in Richtung des gefahrvollen arabisch besetzten Südens auszurichten und nicht in den abgesicherteren christlichen Norden, ist aus verteidigungstechnischer Sicht nicht zu erklären. In jedem Fall aber sakralisiert diese überdeutlich formulierte Heilserwartung des Relieffrieses inhaltlich die gesamte Burgkirchenanlage, da sie deren Bewohner, seit ihrer Einsetzung durch den aragonesischen König im Jahr 1071 vor allem eine Gemeinschaft von Chorherren, ${ }^{14}$ sich ihrer Sache felsenfest sicher erscheinen lässt.

Rechts neben dem Portal, das zugleich den Haupteingang der Hauptburg bildet, ist eine leicht hochrechteckige Inschriftentafel in den Bauverband eingelassen (Abb.5). ${ }^{15}$ Die Inschrift nennt zu Beginn der dritten Zeile einen ansonsten in den Quellen unbekannten Tulgas, der am 30. November 1095 verstorben sei und sehr wahrscheinlich als einer der aragonesischen Augustinerchorherren der Burgbesatzung die Memorialinschrift vor seinem Tod zumindest noch selbst vorformulierte. ${ }^{16}$

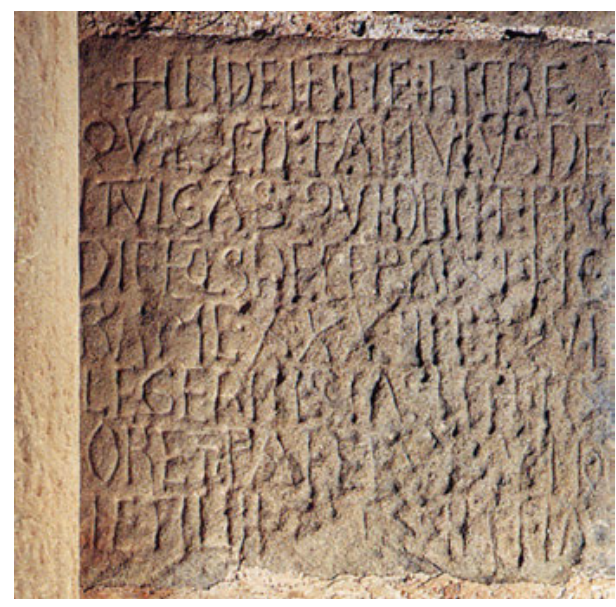

IN DEI N[OMI]NE: HIC RE

QUIESCIT FAMVLVS DE

I TVLGAS QVI OBIIT PRI

DIE K[ALEND]IS DECE[M]BRIS IN E

RA[M?] MCXXXIII [30.11.1095]: QVI

LEGERIT ISTAS LI[T]TERAS

ORET PATRVM E[I]VS VT DO

NET ILLI VITAM SEMPITERNAM ${ }^{17}$

Abb.5: Loarre, Tulgas-Inschrift.

13 Trinks 2010, 17-19.

14 Durliat 1999, 125.

15 Einige Forscher mahnten an, dass es für die eintretenden Besucher aufgrund der Anbringungshöhe kaum eine Möglichkeit gegeben habe, die Bilder des Tympanons und die Inschrift tatsächlich zu lesen, vgl. z. B. Kendall 1998, 94. Diese Bedenken scheinen angesichts des gebauten Plateaus direkt vor dem Burgtympanon sowie der selbst aus Fernsicht guten Sichtbarkeit der - ursprünglich wohl zusätzlich farbig gefassten - Skulpturen nicht nachvollziehbar.

16 Cristóbal Guitart Aparicio bezeichnet sie als „Grabinschrift“, vgl. Guitart Aparicio 2004, 20.

17 Whitehill 1928, 254, liest „requiem serenam“ statt „,vitam sempiternam“. 
Tulgas’ Selbst-Bezeichnung als FAMVLVS DEI - „Knecht Gottes“, die Dritte kaum ungefragt über ihn vorgenommen hätten, ist unter anderem von dem ikonischen Berliner Moses-Thomas-Diptychon vertraut; ${ }^{18}$ es handelt sich um die Stelle in Hebräer 3,5 des „Knechtes Gottes“, wobei die im Mittelalter vielverwendete Formel insbesondere am Hauptportal einer Kirche mit Ernst Robert Curtius vielleicht eher als ,affektierte Bescheidenheit“ gelesen werden sollte. ${ }^{19}$ Wie in der berühmten Tympanoninschrift der nahegelegenen Kathedrale von Jaca wird mit dem Wort LEGERIT ein Apell expressis verbis an einen Leser gerichtet, der im Fall der Besatzung der Burg von Loarre mit großer Wahrscheinlichkeit ein literater Augustinerchorherr war. Betont werden zudem mit LITTERAS die Lettern der Inschrift, was den Leser bereits aufmerksam macht auf diese und etwaige weitere eingemeißelte Inschriften der Burg. Ebenfalls wie in Jaca schließt die Inschrift mit der expliziten Nennung Gottvaters als PATER ab; im Text des Chrismonrings von Jaca (Abb.11) steht das griechische Rho-„,P“ zugleich für das lateinische Pater, das heißt, es wird in zwei der drei heiligen Sprachen der Bibel mit völlig unterschiedlicher Bedeutung aufgeladen. Die Tulgas-Inschrift schließt mit der Bitte, den Verstorbenen Gott anzuempfehlen, damit dieser ihm ewiges Leben schenke. Aus heutiger Sicht wirkt die Betonung der erbetenen Vermittlung selbstverständlich, in den nordspanischen Königreichen jedoch ist sie von großer Bedeutung, da beispielsweise in Aragón erst an Ostern des Jahres 1071 in der vom selben König Sancho Ramírez gegründeten Klosterkirche San Juan de la Peña der erste lateinische Gottesdienst in diesem Königreich zelebriert wurde und die vom König im selben Jahr auf der Burg eingesetzten Chorherren direkt dem Heiligen Stuhl in Rom unterstellt waren. ${ }^{20}$ Damit war der alte westgotische Ritus mit seiner abweichenden Auffassung von Fürsprache bei Gott abgelöst. ${ }^{21}$ Die fast durchgängig dem römischen Apostelfürsten Petrus geweihten Kirchengründungen König Sancho Ramírez' mit ihrer wiederholten Anrufung der Dreifaltigkeit sind daher kein Zufall, vielmehr kirchenpolitisches Kalkül, seit der aragonesische König 1068 den Papst persönlich in Rom aufsuchte. ${ }^{22}$ Die Schrifttafel erweist sich damit als mehrfach interessegeleitete Memorial-Grabinschrift unmittelbar unterhalb der Paradiesesdarstellung des Türsturzreliefs.

Nach Durchschreiten des Portals mit seiner buchstäblich erhebenden Heilsverheißung darüber setzt sofort eine weitere Elevation ein. Ohne Zwischenpodest, das heißt ohne die bauliche Möglichkeit zum Innehalten, steigt eine Treppe derart steil

18 Frese 2014, v. a. 11 und Trinks 2002, 37.

19 Der antike Topos der „affektierten Bescheidenheit“ findet sich exemplifiziert bei Curtius 1948, 93-95 und 410-415. Interessant scheint, dass der wiederkehrende Topos den eigentlichen Anspruch in das sprachliche Gewand vorgeblicher Selbstbeschränkung einhüllt, und dies bedeutet auf Kunstwerken oder im Rahmen von Architektur konkret immer die Schriftform. Unterschiedliche Fälle dieser unbescheidenen Selbstentlarvungen in schriftbildlicher Form durch eben ihr Erscheinungsbild bei Trinks 2013.

20 Durliat 1999, 125.

21 Vgl. z. B. Bartal 1987, 299-315 sowie Bronisch 2005, 161-189.

22 Die ausufernde Diskussion hierzu fasst bündig zusammen García García 2011 und 2012. 


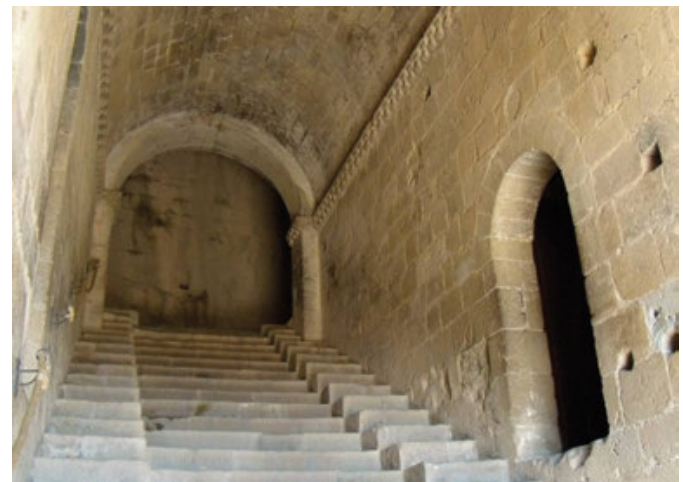

Abb. 6: Loarre, Treppe.

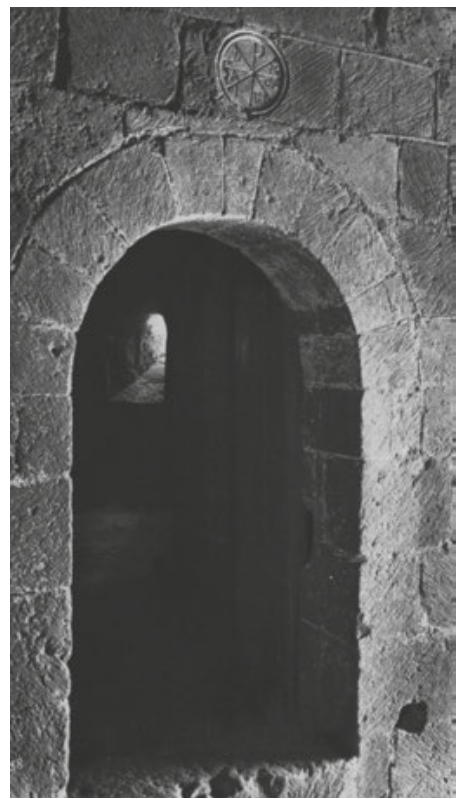

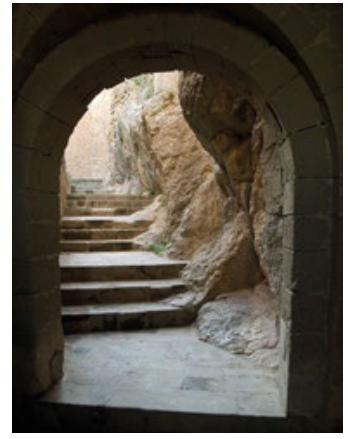

Abb. 7: Loarre, Treppenausgang und Weg zur Oberkirche.

Abb. 8: Loarre, Unterkirche, Portal.

nach oben (Abb.6), dass sie den Besucher der Burg wie eine Jakobs- oder byzantinische Himmelsleiter des Johannes Klimatikos geradewegs aus dem dunklen Gang zur lichtdurchfluteten Oberkirche führt (Abb.7). ${ }^{23}$ Die Burgkirche wiederum auf einem Tafelberg ist mit ihrem Peterspatrozinium nicht nur symbolisch auf Petros-Fels gegründet, sondern auch buchstäblich, da im Westteil der Kirche Fels steinsichtig stehen gelassen wurde. ${ }^{24}$

23 Zur Ikonographie der Himmelstreppe vgl. Schmidt/Schmidt 1984, 254-255.

24 Der Architekturhistoriker Jesús Maria Caamaño Martínez hat festgehalten, dass bereits auf dem 


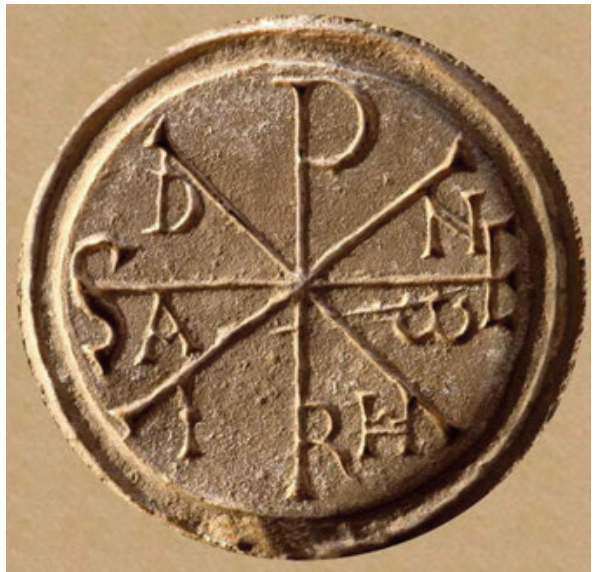

Abb. 9a: Chrismon, isoliert.
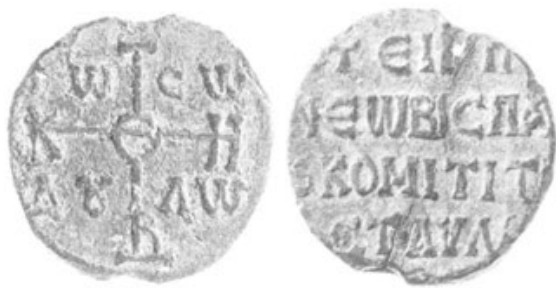

Abb. 9b: Byzantinisches Bleisiegel des Eirenaios, kaiserlicher Spathar und Vorsteher der kaiserlichen Stallungen.

Anstatt allerdings nahtlos dem Sog nach oben $\mathrm{zu}$ folgen, unterbricht eine schmale, hochgezogene Türöffnung auf der rechten Seite mit einer in die Wand eingelassenen und neugierig machenden Rundform (Abb.8) die direkte Elevation des Besuchers. Indem die Tür erst eine Steinlage über der Treppenstufe beginnt, muss dessen Körper eine relativ weit ausholende Bewegung vollziehen, um den Fuß überhaupt auf die Schwelle dieser Raumöffnung setzen zu können. Es gilt, ein Hindernis zu überwinden.

Über dem Rundbogen der Tür ist ein kleines Chrismon (Abb.9a), das antike Christuszeichen Kaiser Konstantins aus den griechischen Anfangsbuchstaben Christi Chi und Rho, dergestalt in die Wand eingetieft, dass es wie eingestempelt wirkt. ${ }^{25}$ Die tiefe Einprägung in die Wand und das beinahe Verschwinden in dieser macht bereits auf den ersten Blick neugierig, die schemenhaft von der Seite bereits zu erkennenden Zeichen zu entziffern. ${ }^{26}$ Dazu kommt, dass sich abweichend von den üblichen

Weg zur Oberkirche ein Wendepodest nach der „Johannes Klimatikos“-Himmelstreppe und Vorausschau auf „Sankt Petros“-Felsen sichtbar als Teil der Treppe stehen lässt, was aus konstruktiven Gründen nicht nur unnötig, vielmehr geradezu störend ist. Wie aufwendig ansonsten an einer makellosen Ästhetik der Burg gearbeitet wurde zeigt die hallenhohe, sehr sorgfältig aus Hausteinen gefügte Quertonne über dem Treppengang, die zwischen dem etwa fünf Meter differierenden Höhenniveau des Treppengang-Wendepodestes und der Treppe Richtung des Eingangs der Oberkirche vermittelt. Vgl. Caamaño Martínez 1993, v. a. 107.

$25 \mathrm{Zu}$ dem meist nach Eusebs Beschreibung gestalteten Konstantinischen Christogramm, das in Europa von Konstantins viertem Jahrhundert an nirgendwo so weit verbreitet ist wie auf der Iberischen Halbinsel, vgl. Ostermann 2017, 255-257.

26 Balke, Keil, Opdenhoff und Stroth betonen an ihrem Fallbeispiel der Kapitell-Monogramme der Hagia Sophia zu Recht: „Die Namensinschriften der [byzantinischen; ST] Stifter sind nicht linear auf Zeilen angeordnet, sondern die Buchstaben werden als Monogramme miteinander verschmolzen (Ligatur, Involution, Juxtaposition). Das Byzantinische Monogramm nimmt, anders als die uns heute geläufigeren Initial-Monogramme alle Buchstaben eines Wortes samt Kasus-Endungen in sich 
verschränkten Charakteren eines Christogramms Chi und Rho hier noch zusätzliche Buchstaben finden, nämlich neben den beiden das Chrismon konstituierenden weitere sieben. Für die Deutung dieser sieben Lettern konkurrieren mindestens drei Lesarten. Während das $\mathbf{X}$ und $\mathbf{P}$ sowie das $\mathbf{A}[\mathrm{lph}$ ] und $\mathbf{\Omega}$ [mega] unumstritten sind, entzündet sich der Streit an den beiden Buchstabengruppen SRE und DNIH. Vorgeschlagen wurde beispielsweise mit der Auflösung „Spiritus Ecclesiae et Rex, Dominus Noster, Impellere Hostes“, „Jesus Christus, Anfang und Ende, Spiritus Rector der Kirche und König, unser Herr, vertreibe die Feinde!" eine explizit politische Lesart, ${ }^{27}$ die Christus als König anspricht und seinen kämpferischen Beistand gegen die Araber fordert. In Analogie mit - allerdings jüngeren - Chrismones des Valle del Ésera wurde das besonders in Rede stehende DNIH auch weniger Reconquista-betont als Dominus Noster IH[e]sus“, „Unser Herr Jesus Christus“ gelesen. ${ }^{28}$

Die Auslegung, die sich in der Forschung inzwischen mehrheitlich durchgesetzt hat, liest das auffällige SRE als Sanctius Radimiriz/Rex Ecclesiae, also Sancho Ramírez, zu ergänzen wäre vielleicht noch „Stifter“ dieser Kirche, aber vielleicht als Kämpfer der Reconquista auch „Schützer“ der gesamten Kirche in Aragón. Damit traut die Lesart dem Erbauer dieser und der anderen sechs Burgkirchen sowie einem der führenden Strategen gegen die Araber diese selbstbewusste Einschreibung in das Zeichen des konstantinischen Chrismon-Kreuzes zu. Dies ist, wie Heinrich Klotz bereits 1976 gezeigt hat, ${ }^{29}$ eine der elegantesten und unverfänglichsten Möglichkeiten, sich unter Berufung auf das Pauluswort im Galaterbrief 6,14 „Ich wolle mich nicht rühmen, es sei denn im Zeichen des Kreuzes unseres Herrn“, an zentraler Stelle unter den direkten Schutz Gottes zu stellen und sich - häufig in ,affektierter Bescheidenheit" - eben doch zu rühmen.

Nachdem die Tulgas-Inschrift einen terminus ante quem 1095 für den gesamten Bereich der Treppe und den Raum hinter der Tür setzt, ist dieses Chrismon aus den 1080er bis frühen 1090er Jahren eines der ältesten Spaniens im Bauverband; in jedem Fall scheint seine Form und sein Buchstabenreichtum in dieser Zeit einzigartig zu sein, weshalb geradezu zwangsläufig die Frage gestellt werden sollte, ob es nicht doch mögliche Inspirationsquellen gibt.

Als eine neue These sei hier vorgestellt: In der auffälligen Kleinheit des LoarreChrismon mit nur etwa 30 Zentimeter Durchmesser und seinen deutlich artikulierten additionalen Lettern, vor allem dem SRE, die hier offensichtlich keine Christusnamen sondern Namensinitialen verkörpern, ähnelt es byzantinischen Bleisiegeln

auf. Diese besondere Schreibweise behindert den ,Lesenden Blick ${ }^{\star}$ und so kann eine diskursive Rezeption nur als ,Entziffern` erfolgen. Als retardierendes Moment der Rezeption befördern Monogramme die ästhetische Wahrnehmung ihrer artefaktischen Präsenz“. Vgl. Balke/Keil/Opdenhoff/Stroth 2015, 264-265.

27 Diese stammt von Francisco Matarredona Sala, vgl. Matarredona Sala 2003, 55.

28 Matarredona Sala 2009, 18.

29 Klotz 1976, 302-312. 
(Abb. 9b). ${ }^{30}$ Auf diesen sind in ein zentrales Kreuz oder Chrismon Namensinitialen und Abkürzungen ihrer Würdenämter oder Funktionen eingehängt, ${ }^{31}$ wie auf dem abgebildeten Siegel beispielsweise das griechische I und ein $\mathrm{K}$ bei Eirenaios, dem kaiserlichen Spathar und Vorsteher der Stallungen. Derartige Bleisiegel kursierten zu Hunderten noch lange nach der byzantinischen Herrschaft auf der Iberischen Halbinsel und wurden bis ins hohe Mittelalter teils als entindividualisierte Siegelringe weiterverwendet oder als wertvoll erachtete Grabbeigaben den Verstorbenen mitgegeben. ${ }^{32}$

Der Charakter eines Siegels wird insofern betont, als das Chrismon nicht - wie in Spanien üblich - ein glattes Randprofil aufweist, sondern von einem breiten, leicht unregelmäßigen Wulst gerahmt wird, wie er sich erfahrungsgemäß beim Einprägen einer Petschaft in Siegelwachs aufwirft. Bei dem Chrismon der Unterkirche von Loarre handelt es sich um eines der wenigen Chrismon-Darstellungen, die nicht im Hochrelief von einer Fläche abstehen, vielmehr tief in eine Wand eingeprägt sind. Zusätzlich sind die neun Lettern jeweils noch in die Nullebene eingetieft, indem anscheinend ein dreiecksförmiger Grat in den Stein eingeschlagen wurde. Die Perfektion des Steinschnitts und die Anmutung des anscheinend nicht von Menschenhand Eingeprägten besitzen durch den Zwang zum Hochblicken etwas Dignifiziertes und Erhaben-Göttliches, so dass der Chrismon-,,Stempel“ wie ein Acheiropoieton wirkt, mit dem der Eingang zur Unterkirche von göttlicher Hand markiert wurde, ${ }^{33}$ ähnlich wie Aaron in Ägypten mit einem Taph-Kreuz die Häuser der Israeliten schützte und die Israeliten zum Heilszeichen Eherne Schlange am Kreuz aufblicken müssen, um zu gesunden. ${ }^{34}$

30 Vgl. Das byzantinische Bleisiegel 1997, 71 und 81-82.

31 Das Abhängen von Namensinitialen findet sich auf der Iberischen Halbinsel spätestens seit den asturischen Gold-Edelsteinkreuzen des neunten Jahrhunderts, vgl. Castro Valdés 2013, 103-124.

32 Insbesondere der Byzantinist Philipp Schweinfurth richtete früh sein Augenmerk auf die weite Verbreitung der byzantinischen Siegel ab etwa 1050 bis zum Beginn des 13. Jahrhunderts, auf ihre antike Abkunft und Rezeption. Als plastisches Beispiel dient ihm ein Bleisiegel des Klosters Daphni bei Athen, das auf seiner Vorderseite die Blacherniotissa zeigt, auf der Rückseite aber in wohlgesetzten Worten „Sphragis proedra Paulu poimnes Daphniu“, „Dies ist des Abtes Paul von Daphni Siegel hier“ das Siegel hervorhebt. Dabei betont Schweinfurth, dass der angewandte Justinische Trimeter, der als übliches Versmaß der „griechischen Tragödie im Amphitheater am Abhang längst verstummt“ sei, auf den mittelbyzantinischen Mönchssiegeln weiterlebt. Die byzantinische Schriftfixiertheit und -verliebtheit erklärt und charakterisiert er als „Herrschaft der schönen Linie“ insbesondere unter den Paläologen. Vgl. Schweinfurth 1943, v. a. 33 sowie generell zu gelehrten Versformen in Inschriften Christian 2015.

33 Schreiner 2003, v. a. 95-97.

34 Für den quasigöttlichen Zwang zum Aufschauen siehe den Katalog Der himmelnde Blick 1998. Für Schrift als Heils-Zeichen Becht-Jördens 2015, für den Vergleich eines Chrismon mit der Ehernen Schlange siehe Trinks 2012, 51-56. Die Anregung, dass mit dem Einstempeln des Namens des Gottessohnes und mit Alpha und Omega auch apokalyptischen Opferlamms ebenfalls ein eucharistischer Gehalt der Prägung einer Wand aus den lebendigen Steinen der Gläubigen alludiert sein kann, verdankt sich Tobias Frese. Für die theologischen Konzepte hinter den bildhaften mittelalterlichen Hostienstempeln vgl. Frese 2013. 


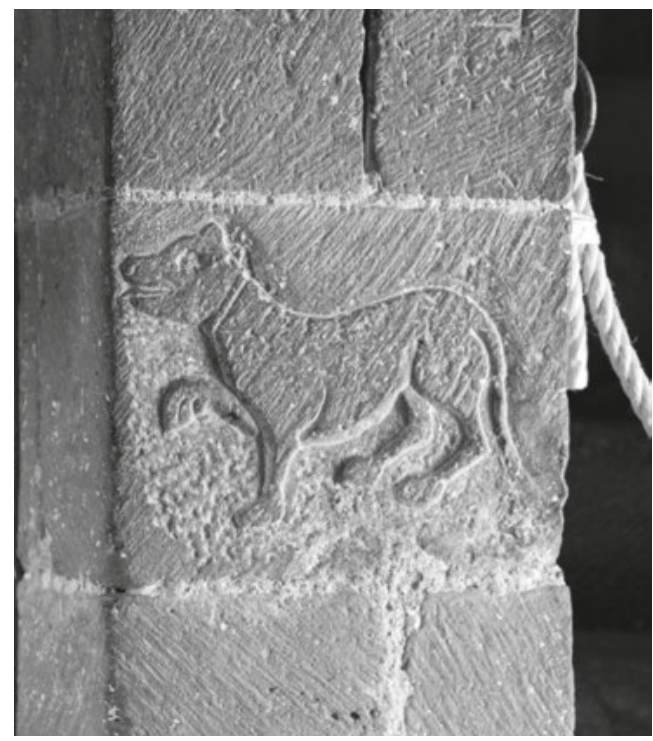

Abb.10: Loarre, Löwe mit erhobener Pranke.

Den Schriftzeichen auf Siegelsteinen wurde in Antike und Mittelalter oft eine magische oder schadensabwendende Wirkung zuerkannt. ${ }^{35}$ Die apotropäische Wirkung, die das Kreuzeszeichen des Chrismon, ${ }^{36}$ noch verstärkt durch die eingehängten Invokationslettern, ${ }^{37}$ seit Alters her besitzt, setzt sich in zwei figürlichen Darstellungen an diesem Portal fort, die bislang nicht publiziert sind.

An der rechten Türbogenwange ist etwa auf Hüfthöhe ein Vierbeiner in Flachrelief zu sehen (Abb.10), der die rechte Pranke erhoben hat und - wenn man sich die Portalwange Richtung Scheitelpunkt der Tür eingeklappt imaginiert - dem Chrismon mit geöffnetem Maul und heraushängender Zunge entgegentritt. Um den Hals trägt das Tier ein dünnes glattes Band, sein Schwanz mit leichter Quaste fällt in einem Bogen bis auf das Niveau der im Vergleich zu den vorderen Pranken leicht erhöhten

35 Der Einsatz von Schrift als Schutz insbesondere in islamischen, d. h. größtenteils ehemals byzantinischen Einflussgebieten ist gut aufgearbeitet in Power and Protection 2016, z. B. 38. Aber auch an die Austauschprozesse und das Einwandern islamischer Artefakte mit Schrift in den christlichen Bereich ist zu denken wie etwa an das Siegel mit dem Namen Allahs in einem Goldkreuz aus Irland des 9. Jahrhunderts, die Gemme mit Anrufung Allahs auf dem Deckel des Perikopenbuchs von Kaiser Heinrich II., den mit spiegelbildlicher Schrift versehenen Gemmenring der Ermesenda im Kathedralschatz von Gerona des 11. Jahrhunderts oder die Sakralisierung von eingravierter Schrift auf fatimidischen Kristallgefäßen desselben Jahrhunderts, die häufig als christliche Reliquiare in Kirchenschätzen genutzt wurden.

36 Das wohl älteste, von Ende des 8. oder Beginn des 9. Jahrhunderts stammende, Kreuz mit unmissverständlicher apotropäischer Inschrift ist abgebildet im Codex Salem X. 12a der Heidelberger Universitätsbibliothek, vgl. Bischoff 1967, 284-285, mit ausführlicher Diskussion der Datierung über die Schrift und einem weiten Ausgriff auf die Kreuzes-Ikonographie.

$37 \mathrm{Zu}$ den spanischen Invokationslettern vgl. Eisenlohr 1994. 


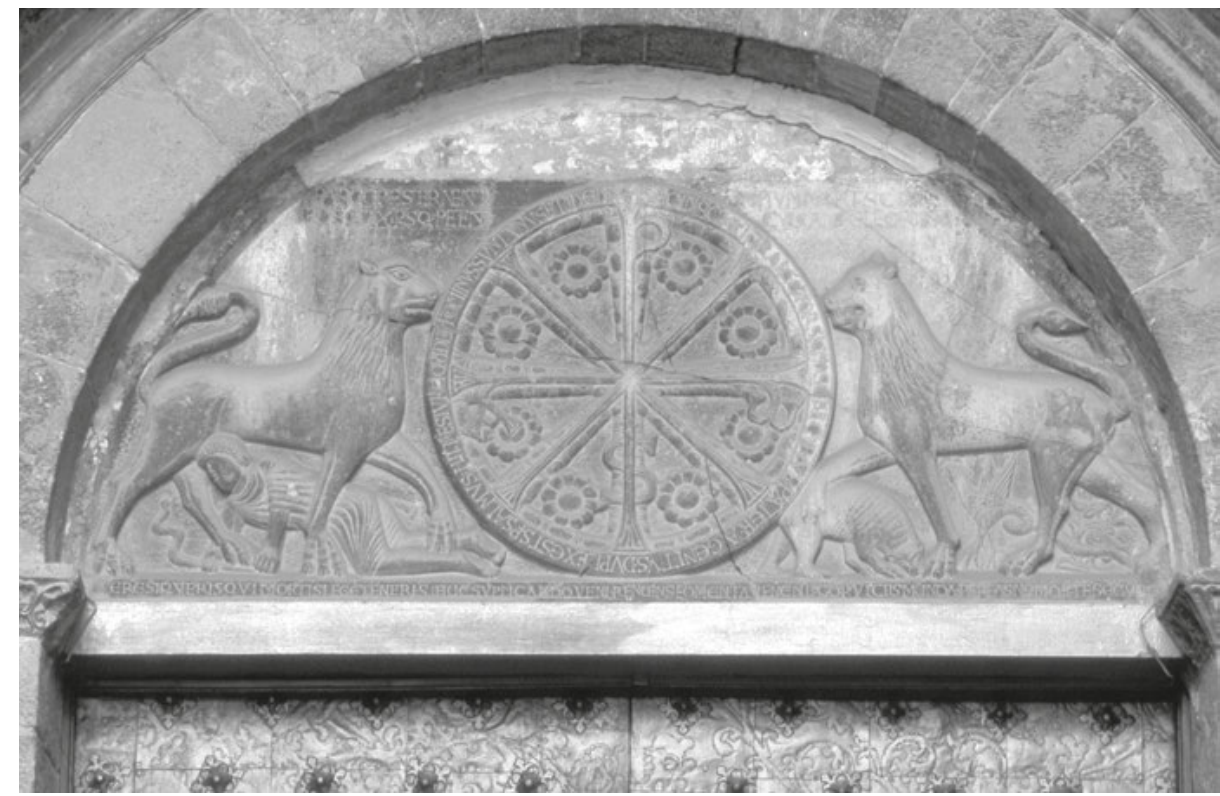

Abb. 11: Jaca, Tympanon.

Hinterläufe. Aufgrund des Schweifes, der gedrungenen Kopfform sowie der runden Ohren scheiden Wolf und Hund wohl aus; es wird sich um die stark vereinfachte Darstellung eines weiblichen Löwen handeln, wie sie gleich mehrfach im näheren Umkreis der Burg von Loarre in vergleichbarer Form erscheint (Abb. 11). Meist im Portalbereich und dort häufig im Tympanon haben diese Löwen, oft wie in Jaca oder im nahen Santa Cruz de la Seros durch Inschriften unzweifelhaft als solche benannt, wie ein übergroßes antikes Cave Canem, „Vorsicht vor dem (bissigen) Hund!“, apotropäische Wirkung insofern, als sie Übelwollende oder Ungläubige vom Eintreten in den Sakralraum abhalten oder diese gar vernichten sollen.

Gegenüber der Raubkatze hingegen ist ebenfalls in die Türwange das Brustbild eines Mannes mit enorm kantigem Kinn, fliehender Stirn, kaum artikuliertem Strichmund und schulterlangen Haaren in einen Steinquader gemeißelt, die sich im Nacken aufwerfen (Abb. 12a). Seine markanten Züge finden eine Parallele auf den Silbermünzen Aragóns in dieser Zeit, die König Sancho Ramírez in der nahen Hauptstadt Jaca prägen ließ (Abb.12b). Zusammen mit der von den meisten spanischen Forschern vorgeschlagenen Lesart des Chrismons als Erweiterung auf Sancho Ramírez über dieser Reliefdarstellung wäre eine den Schwellenraum sichernde Trias aus Wächtertier, Stifter und Christus gegeben, weil letzterer symbolisch in den aufgeladenen Schriftzeichen des Christogramms verkörpert ist. Durch den bereits im Chrismon ebenfalls präsenten Stifternamen von Sancho Ramírez und das offenbar von einem auf das Wesentliche stilisierten Münzbild übernommene, in den Stein gravierte Bildnis des Königs im Profil, wird dieses gleichsam ,mit-sakralisiert‘. Insbesondere aber werden 

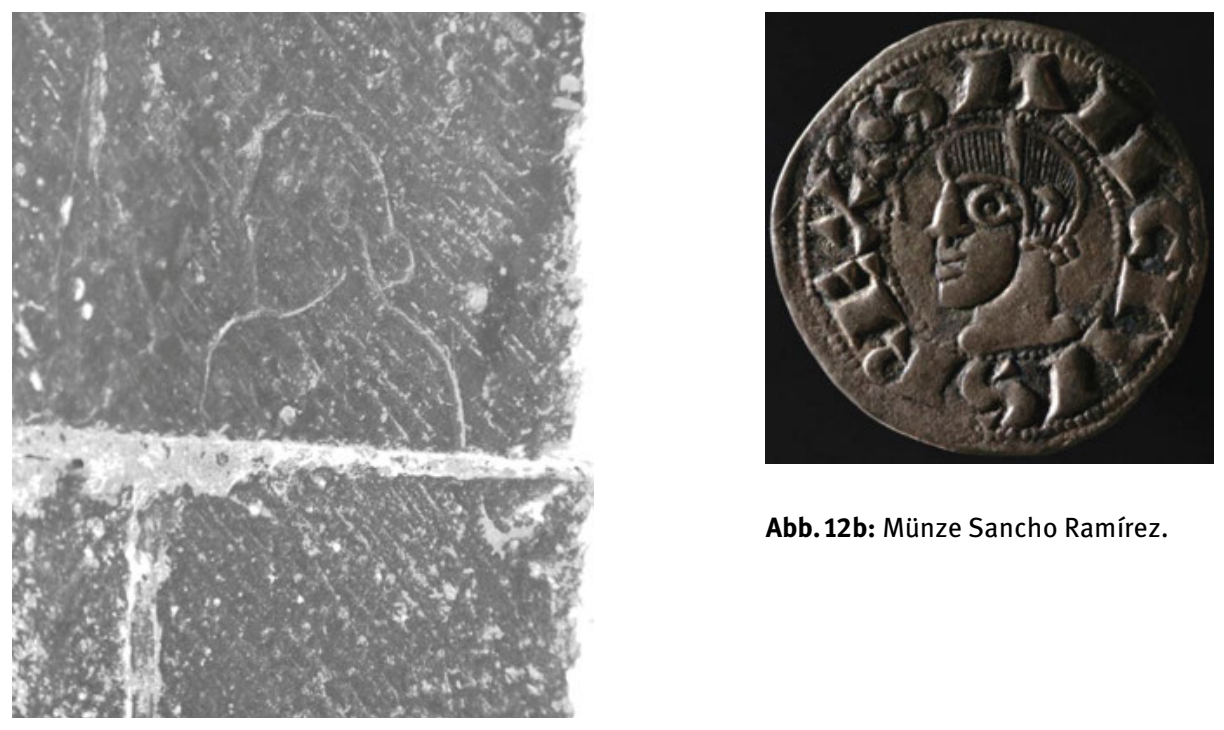

Abb.12b: Münze Sancho Ramírez.

Abb.12a: Loarre, Türwangenrelief, Sancho

Ramírez.

Ritzzeichnung und Namens-Chrismon durch den Inhalt des Raumes hinter dem dreifach markierten Portal ausgezeichnet:

Tritt man in diesen bereits im Außenbereich mehrfach sakralisierten Raum, erkennt man im Halbdunkel des in raffinierter Lichtregie nur durch drei Schlitzfenster beleuchteten Kuppelraumes einen Altar mit glatter Mensa, wobei die Halbkuppel wie ein Trichter nicht nur für eine herausragende Akustik sorgt, sondern auch den Blick wiederum in Richtung des Chrismon am Portal zurückführt. Auf der Altarmensa wurde wohl zumindest an hohen liturgischen Festen ein byzantinisierendes Reliquiar aus vergoldetem Silber präsentiert (Abb.13b). ${ }^{38}$ Eindrucksvolle 61 mal 30 Zentimeter lang, ${ }^{39}$ barg es die Reliquien des neben Georg zweitbedeutendsten ostkirchlichen Ritterheiligen Demetrios, die König Sancho Ramírez von Aragón vielleicht als Dank für Waffenhilfe für den byzantinischen Kaiser gegen muslimische Truppen direkt aus der Hauptstadt Byzanz erhalten hatte. ${ }^{40}$ Unter Arkaden, die zwischen Pilaster mit Ranken-

$38 \mathrm{Vgl}$. den ersten ausführlicheren Eintrag zu diesem ansonsten kaum bekannten Reliquiar in Signos 1993, 109.

39 Vgl. Durliat 1999, 125.

40 Da König Sancho Ramírez durch die Heirat mit der französischen Adeligen Felicia von Roucy in der frühen Reconquista enge Beziehungen zu der französischen Kreuzzugsbewegung über Byzanz hatte, kann der Weg der Demetrios-Reliquien als Entlohnung für Waffenhilfe ein ähnlicher wie der in St-Sernin de Toulouse von Partikeln von nicht weniger als sechs Aposteln sowie der Gemma Augustea, einer kaiserlich-römischen Großgemme wohl aus Konstantinopel, gewesen sein, die ebenfalls als Kriegssold Eingang in den Kirchenschatz der Pilgerwegskirche fanden. Vgl. Trinks 2012, 302-305. 


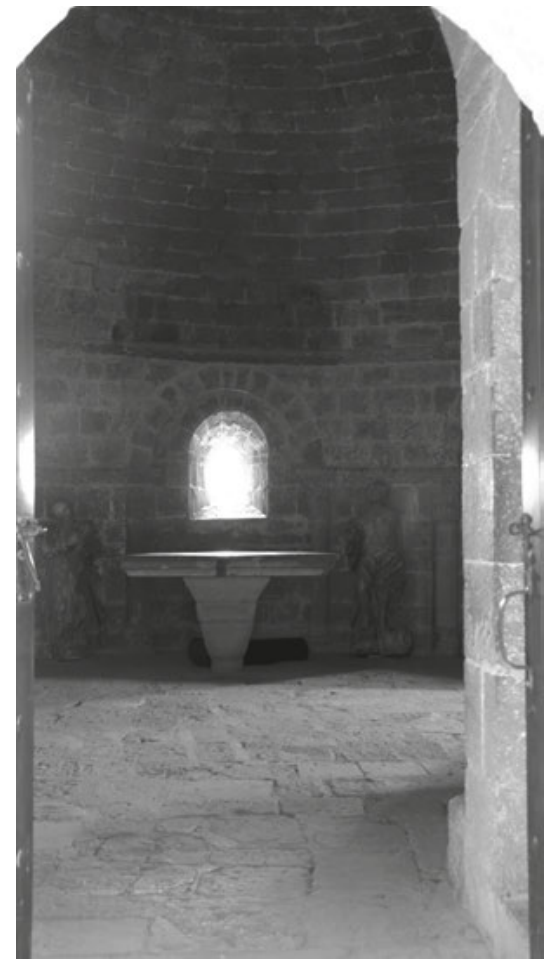

Abb. 13a: Loarre, Unterkirche mit Altar .

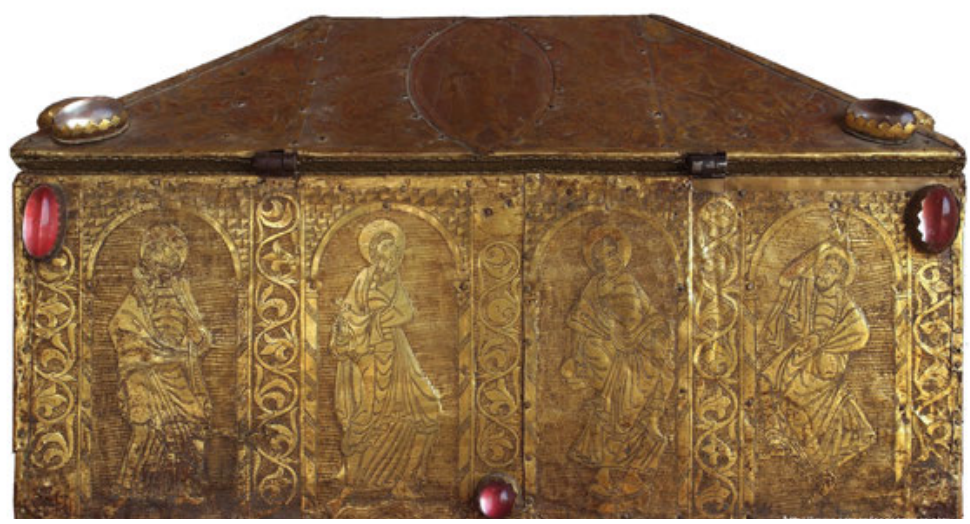

Abb.13b: Demetrios-Reliquiar. 
werk eingestellt sind und deren Zwickel mit durch Schattierung plastisch gestalteten Quadern graviert sind, stehen vor einem mit Tremolierstrich dunkel-flirrend gemusterten Grund die zwölf Apostel. Sie sind derart bewegt gezeigt, dass sie wie der rechts zu sehende teils zu tanzen scheinen. Sie bilden symbolisch die tragenden Säulen des Reliquiargebäudes, das von einem Walmdach mit Christus in der Mandorla, umgeben vom Tetramorph und weihräuchernden Engeln, bekrönt wird. Mit den ungewöhnlicherweise in das obere Drittel der Mandorla eingehängten apokalyptischen Zeichen Alpha und Omega wird eine wesentliche Aussage des Eingangs-Chrismon durch das Reliquiar aufgenommen. Vor allem aber greift es mit der verdoppelten Darstellung von Christi Wiederkehr mit Tetramorph und der durch den Gottessohn vorvollzogenen leiblichen Auffahrt in den Himmel die klar formulierte Verheißung des Hauptportals der Kirchenburg mit seiner Konzentration allein auf die Seligen auf: Als Belohnung bei Wohlverhalten ist für die Regularkanoniker der Höhenburg das ewige Leben, um das Tulgas in der Inschrift am Eingang bat, in Reichweite gerückt.

Der Schrein kann anhand stilistischer Vergleiche mit südfranzösischen, vor allem aquitanischen Handschriften und seines byzantinischen Einschlags in das ausgehende elfte Jahrhundert datiert werden. ${ }^{41}$ Damit stammt er aus der Erbauungszeit der Burgkirche von Loarre, so dass die Unterkirche tatsächlich bewusst als zweite bauliche Hülle für diese kostbaren und wahrscheinlich schon vorhandenen Reliquien geschaffen worden sein kann. ${ }^{42}$ Dieser mit seinen nur drei Schlitzfenstern betont dunkel gehaltene Raum um den architektonisierten Goldschrein mit seinen Quadern herum sakralisiert mit dem zu seiner zumindest partiellen Beleuchtung unabdingbaren Fackellicht die Präsentation des Demetrios-Reliquiars auf dem Altar zusätzlich. Bekrönt wird die stark betonte Präsenz des Schreins dieses ostkirchlichen Ritterheiligen in seiner Alterität durch das byzantinisierende Siegel über dem Eingang zu diesem Sakralraum. ${ }^{43}$

Wie gesehen, bürgt an dem der Wand wie eingeprägten Schwellensymbol Chrismon der Stifter mit seinem Namen und mit seinem Konterfei für den Schutz dieser Reliquien wie auch des materiell wertvollen Schreins. Das animalische Apotropeion des Löwen an der Türwange mit abwehrend erhobener Pranke besitzt die Zwiegestalt eines ,mehrdeutigen Symbols ${ }^{6}{ }^{44}$ Er ist abschreckender Wächter, Cave Canem und herrscherliches Symbol zugleich. In seiner Polyvalenz scheint er wie auch das Chrismon von dem zeitlich vorausgehenden Kathedralportal in Jaca geprägt.

41 Durliat 1999, 125.

42 Das gleichsam frühchristliche Element dieses gebauten Reliquienumgangs betont Marta Poza Yagüe, vgl. Poza Yagüe 2009, 68.

43 Zur weiteren Sakralisierung dieser Burgkapelle der Heiligen Quiteria beispielsweise durch das bautechnisch aufwendige Kuppelgewölbe vgl. Matarredona Sala 2003, v. a. 52-54.

44 Gier 1985, 189-200. 


\section{Jaca - Sehen und Lesen}

Die ab 1076 von König Sancho Ramírez errichtete Kathedrale San Pedro de Jaca als erste Station des spanischen Pilgerweges nach Santiago wird durch eine monumentale Vorhalle im Westen betreten. ${ }^{45}$ Als erster Teil der Bischofskirche entstand das mächtige trichterartige Portal mit dem ältesten teilfigürlichen Tympanon der Romanik auf der Iberischen Halbinsel (Abb.11). Flankiert von zwei Christus symbolisierenden Löwen - der linke legt seine Pranke schonend auf einen sich niederwerfenden Büßer im härenen Gewand mit der Schlange der Erbsünde in der Hand, ist im Zentrum ein Chrismon zu sehen. Auf den Zeilen ${ }^{46}$ über dem links schreitenden Löwen steht zu lesen: PARCERE STERNENTI LEO SCIT XRISTVSQVE PETENTI, das heißt: Der Löwe weiß den sich vor ihm Niederwerfenden $\mathrm{zu}$ verschonen wie Christus den Bittenden. Dies ist eine von mehreren auf dem Tympanon zu findenden Paraphrasen aus den Tierbeschreibungen der spätantiken Etymologiae Isidors von Sevilla, ${ }^{47}$ der seinerseits Plinius mit der Naturalis Historia zitierend schreibt: „Patet enim eorum misericordia exemplis assiduis. Prostratis enim parcunt [...]“, ${ }^{48}$ also, dass der Löwe dem Menschen gegenüber in wiederholten Beispielen Milde gewährt hat und den sich vor ihm Niederwerfenden schont. Wie es vor dem Adamsportal von St.-Lazare in Autun mit der nach dem Sündenfall kriechenden Eva nachweisbar ist, ${ }^{49}$ diente auch dieser durch Chrismon, Bilder damals sicherlich furchteinflößender Löwen und Bußanleitungs-Inschriften hochsakralisierte ,Vor-Raum‘ für öffentliche Bußgottesdienste Königs Sancho Ramírez und seines gesamten Gefolges. Erst nach vollzogener Buße durfte die Schwelle unter dem Chrismon wieder überschritten werden. Der ChristusLöwe rechts fungiert als übergroßes Animal-Apotropeion insofern, als er, wie es in der Inschrift über ihm beschrieben wird, die Vertreter des Bösen als Gegenbild zum Verschonen des Bußfertigen gemäß Psalm 90,13 mitleidlos zermalmt und allein durch seine monumentale Präsenz Übelwollende vom Betreten des Sakralraums abschre-

$45 \mathrm{Zu}$ den Spezifika von Inschriften an Pilgerwegen vgl. Dünne/Doetsch/Lüdeke 2004, hier v. a. den Abschnitt zu Räumlichkeit und Schriftkultur.

46 Obwohl im Grunde überflüssig, zitiert der Schrifthauer bei den Inschriften über den Löwen mit der genauen Linierung unter den Lettern das Ordnungsgerüst der antiken Quadratarii.

47 Die Bedeutung Isidors als neben Jakobus zweitem „Nationalheiligem“ Nordspaniens wie auch im Rahmen einer „kulturellen Reconquista“ kann kaum hoch genug eingeschätzt werden. Selbst für die Auswahl der künstlerischen Themen spielt die inhaltliche Auseinandersetzung mit diesem wichtigsten Enzyklopädisten des Mittelalters, der um 620 das gesammelte Wissen der Antike in den zwanzig Bänden seiner Etymologiae überliefert, eine entscheidende Rolle. Vgl. Trinks 2009, hier v. a. 220-221. Die Etymologiae sind inzwischen auch in einer sehr guten deutschen Übersetzung leichter zugänglich, vgl. Die Enzyklopädie 2008, 455-456. Dort findet sich im zwölften Buch „Von den Tieren“ das Kapitel zum Löwen.

48 Plinius, Naturalis Historia 19, 48ff. Hier zitiert nach der unverändert maßgeblichen Edition von Wallace M. Lindsay, vgl. Etymologiarum 1911, XII, 2, 6.

49 Vgl. Werckmeister 1972, 18. 
cken kann. Das im Tympanonzentrum stehende, monumentale Christuszeichen der von gebildeten Augustinerchorherren geführten Kirche in Jaca ist im mehrfachen Augustinischen Wortsinn aufgeladen, denn durch eine Inschrift auf dem Rad ist es sowohl um eine trinitarische Komponente erweitert (die das P als Pater und das VNVS ET QVIDEM erläutern), ${ }^{50}$ als auch durch die zwischen die Speichen gesetzten Margeriten und die auf dem Horizontalbalken eingehängten Lettern Alpha und Omega um apokalyptische Konnotationen. ${ }^{51}$ Wesentlich erscheint jedoch seine ursprüngliche Abkunft von dem Siegeszeichen Kaiser Konstantins, ${ }^{52}$ mit dem der aragonesische König Sancho Ramírez I., der die Kathedrale stiftete und seinen Bruder Garcia als Bischof investierte, in der beginnenden Reconquista offensichtlich ein politisches Zeichen setzen wollte.

Allein in das Rad dieses Chrismons hat der Schrifthauer 97 Lettern derart präzise eingemeißelt, dass die Inschrift punktgenau vor dem griechischen Kreuz als Startpunkt endet. Kaum glaubwürdig erscheint bei dieser Überfülle an Schrift, dass der Künstler ohne eigene Durchdringung nur Vorgaben oder Vorzeichnungen umgesetzt hätte. Insbesondere die direkte Aufforderung an den ,Leser' der Inschrift, das, was in der Skulptur verborgen sei, mit Sorgfalt wahrzunehmen und zu erkennen (HAC IN SCVLPTVRA LECTOR SI C[OG]NOSCERE CVRA), kann als explizite Leseanleitung seitens der vermeintlichen theologischen Urheber des komplexen Programms von Jaca gewertet werden. ${ }^{53}$ Es handelt sich um einen Übertrag der Sprechakt-Theorie als agierendes und Anweisungen gebendes Bildwerk innerhalb einer sprachfähigen Ecclesia als allegorischem Gesamtorganismus. ${ }^{54}$ Bei einer derart unauflöslichen Verzahnung von Bild und Schrift wäre zuvorderst an den Schrifthauer und den Bildhauer zu denken, die erkennbar des Lateinischen mächtig waren und stolz ihr - bei dieser inhaltlichen Komplexität unabdingbar gemeinsam mit Theologen entwickeltes - Schrift-Bild-Programm präsentieren, mithin ein veritabler Schriftakt, wie Tobias Frese und Wilfried E. Keil pointierten. ${ }^{55}$ Obwohl es auf dem Tympanon keine namentliche Nennung gibt, ${ }^{56}$ hat der Schrifthauer mit dem selbstbewussten HAC IN SCVLP-

50 Zur Geschichte und institutionellen Verfassung von Jaca vgl. García García 2012, v. a. 123-126. Zu den Inschriften z. B. Favreau 1996 und Ocón Alonso 2004, v. a. 218. Dort auch in den Fußnoten 2 und 3 eine Literaturübersicht der reichen Forschung zu diesem ersten monumentalen Figurentympanon Europas.

51 Zum apokalyptischen Gehalt des Tympanonprogrammes, vgl. Caldwell 1980, 25-40.

52 Den bewussten Rückgriff des Jaqueser Chrismon auf das frühchristliche Siegeszeichen hat Dulce Ocón Alonso herausgearbeitet, vgl. Ocón Alonso 2004, v. a. 223-224.

53 Insbesondere Caldwell 1980, 29-32. Inzwischen vgl. auch Kingsley 2012, 171-184.

54 So beispielsweise Kendall 1998, 408 sowie Kendall 1996, v. a. 117.

55 Frese/Keil 2015.

56 Hingegen existiert auf einem besonders prächtigen ornamentalen Kapitell der dem Westportal nächsten Säule der nördlichen Langhausseite eine Künstlerinschrift. Vollkommen überraschend hat ein passionierter spanischer Photograph Ende 2009 bei einer extremen Vergrößerung dieses Kapitells nicht nur eine bislang unpublizierte, unter einem Kapitellblatt hervorkriechende Schlange entdeckt, 
TVRA - sicher im Auftrag des Kathedralstifters Sancho Ramírez - das zur vollendetsymmetrischen Kreuzform erweiterte Chrismon zu einem unverwechselbaren Zeichen gemacht. ${ }^{57}$ Wer Sancho Ramírez' Namens-Chrismon in Loarre kannte, verstand auf Anhieb dasjenige von Jaca, und vice versa.

\section{Triadische Deutungen}

Die gesehenen Inschriften respektive Schriftzeichen-Eintragungen im Fall des LoarreChrismonsiegels markieren mit ihren je inhärenten theologisch-politischen Konzepten Knotenpunkte in einem vielschichtigen Geflecht von Bedeutungen und liturgischen Handlungen im Sakralraum, der Oberkirche, und bereits in ihrem Vorfeld, vor dem Betreten der Räume selbst, am Portalrelieffries. Die Inschriften dienen ebenso der Binnendifferenzierung des architektonischen Raums, der Akzentuierung theologischer Bedeutung und der Betrachterlenkung. Während außen auf dem Relieffries dem Besucher der Burg, der notwendigerweise durch diesen Eingang treten musste, die feste Heilserwartung ,plakativ‘ vor Augen gestellt wurde und Tulgas mit seinem in der Inschrift unmissverständlich vorgebrachten Anliegen den Leser geradezu frontal angeht, wird im Inneren subtil bis uneindeutig in Form der zeichenhaften ChrismonLettern und Relief-Bilder der Türwangen eine Hoffnung auf Heil für den Stifter der Anlage und des Demetrios-Reliquiars, König Sancho Ramírez formuliert, sowie Apotropäisches, das am Portalfries des Außenbaus fehlt, nach Innen geholt.

Der sakrale Schriftraum der Burg von Loarre kann als ein doppelt triadischer beschrieben werden: zum Einen werden kulturell heterogene Konzepte zusammengebracht, indem Römisch-Katholisches ältere westgotisch-mozarabische Traditionen ersetzt und sich in Form des Demetrios-Reliquiars mit Ostkirchlichem mischt. Zum Anderen sind in der Triade Bild-Schrift-Zeichen die Heilsbilder der Seligen des Portalfrieses ebenso eindeutig formuliert, wie Tulgas unmissverständlich seine Erwartung direkt unterhalb des Frieses in der wortreichen Inschrift äußert, während die Schrift des Chrismon im Innern in ihrer extremen Verknappung auf die Anfangsbuchstaben für Heutige nicht mehr ohne Weiteres lesbar ist; die Schriftzeichen-Lettern werden

welche sich zu den ohnehin zahlreichen Schlangen in Jaca gesellt (Vgl. Trinks 2009, 226-231), sondern auch den in das Kapitell eingemeißelten Namen BERNARD[US]. Diese aufsehenerregenden Funde sind im Forum auf der Seite der sehr engagierten Amigos del Románico in exzellenten Aufnahmen dokumentiert: http://www.amigosdelromanico.org/phpBB/viewtopic.php?f=1\&t=1017 (15.9.2017).

57 Dabei spielen sie bewusst oder unbewusst mit der multisensorischen Erscheinung des konstantinischen Siegeszeichens „,in Wolken“, bei der die Stimme Gottes Kaiser Konstantin mit den Worten IN HOC SIGNO VINCES ebenso zum Sieg aufforderte, wie in Jaca zum richtigen Erkennen der Bilder und Zeichen. Die Schrift auf dem Chrismonrad wird damit als quasi-göttliche Erscheinung legitimiert, wie dies Klaus Schreiner auch für andere eigenhändige „göttliche“ Aufzeichnungen und deren Verwendung in heilsgeschichtlichen Kontexten zeigen konnte. Vgl. Schreiner 2003. 
dekontextualisiert und funktionieren in ihrer Bildlichkeit vollständig erst im Vergleich mit anderen Letter-Bildern auf Chrismones desselben Stifters wie Jaca oder Santa Cruz de la Seros.

Auf all diesen Ebenen hingegen greift eine Sakralisierung: Tulgas befindet sich mit seiner Toten-Inschrift gleichsam ad sanctos, räumlich nur wenige Meter von den Reliquien des Ritterheiligen Demetrios entfernt und direkt unter dem visualisierten Himmel der Seligen in Tüchern, mit denen vermutlich die Besatzung der Burg aus Augustinerchorherren aufgewertet wurde. Nicht zuletzt führt die räumliche wie bildtheologische Pathosformel der steil aus dem Dunkel der Unterkirche nach oben in das Licht führenden ,Himmelstreppe‘ zu einer Sakralisierung der profanen Verteidigungsanlage in Richtung einer festen Burg als irdischer Vorausschau des Himmlischen Jerusalems, womit dessen assoziative Vorwegnahme in Gestalt der Burg von Loarre im Film Kingdom of Heaven gewissermaßen intuitiv erfasst wäre.

\section{Bibliographie}

Assmann, Jan (2012), „Schriftbildlichkeit. Etymographie und Ikonographie“, in: Sybille Krämer/Eva Cancik-Kirschbaum / Rainer Trotzke (Hgg.), Schriftbildlichkeit. Wahrnehmbarkeit, Materialität und Operativität von Notationen, Berlin, 139-148.

Balke, Thomas E./Keil, Wilfried E./Opdenhoff, Fanny/Stroth, Fabian (2015), „Stein“, in: Thomas Meier/Michael R. Ott/Rebecca Sauer (Hgg.), Materiale Textkulturen. Konzepte - Materialien Praktiken (Materiale Textkulturen 1), Berlin / Boston, 247-267.

Bartal, Ruth (1987), „The Survival of Early Christian Symbols in $12^{\text {th }}$ Century Spain“, in: Principe de Viana 48, 299-315.

Becht-Jördens, Gereon (2014), „Schrift im Mittelalter - Zeichen des Heils“, in: Joachim Friedrich Quack/Daniela Christina Luft (Hgg.), Erscheinungsformen und Handhabungen Heiliger Schriften (Materiale Textkulturen 5), Berlin / Boston, 245-310.

Bischoff, Bernhard (1967), „Kreuz und Buch im Frühmittelalter und in den ersten Jahrhunderten der spanischen Reconquista“, in: Mittelalterliche Studien. Ausgewählte Aufsätze zur Schriftkunde und Literaturgeschichte II, Stuttgart, 284-303.

Bronisch, Alexander Pierre (1998), Reconquista und Heiliger Krieg. Die Deutung des Krieges im christlichen Spanien von den Westgoten bis ins frühe 12. Jahrhundert, Münster.

Bronisch, Alexander Pierre (2005), „Die westgotische Reichsideologie und ihre Weiterentwicklung im Reich von Asturien“, in: Franz-Reiner Erkens (Hg.), Das frühmittelalterliche Königtum. Ideelle und religiöse Grundlagen, Berlin / New York, 161-189.

Caamaño Martínez, Jesús Maria (1993), „El románico pleno en el Alto Aragón. Arquitectura“, in: Maria Carmen Lacarra Ducay/Carmen Morte García (Hgg.), Signos. Arte y cultura en el Alto Aragón medieval (Katalog zur Ausstellung in Jaca, Museo Diocesano und Huesca, Sala de Exposiciones, 26. Juni - 26. September 1993), Huesca, 102-109.

Caldwell, Susan H. (1980), „Penance, Baptism, Apocalypse: The Easter Context of Jaca Cathedral's West Tympanum“, in: Art History 3,1, 25-40.

Castro Valdés, César García de (2013), „Some Questions on the Function and Iconography of the Cross in the Asturian Kingdom“, in: Juliet Mullins / Jenifer Ní Ghrádaigh / Richard Hawtree (Hgg.), Envisioning Christ on the Cross, Dublin, 103-124. 
Christian, Timo (2015), Gebildete Steine. Zur Rezeption literarischer Techniken in den Versinschriften seit dem Hellenismus, Göttingen.

Curtius, Ernst Robert (1948), Europäische Literatur und lateinisches Mittelalter, Bern.

Das byzantinische Bleisiegel (1997), Das byzantinische Bleisiegel als Kunstwerk (Katalog zur Ausstellung im Museum für Byzantinische Kunst der Staatlichen Museen Berlin, 1997), hg. v. Werner Seibt/Marie Luise Zarnitz, Wien.

Der himmelnde Blick (1998), Der himmelnde Blick. Zur Geschichte eines Bildmotivs von Raffael bis Rotari (Katalog zur Ausstellung der Staatlichen Kunstsammlungen Dresden, Gemäldegalerie Alte Meister, 11. März 1998 - 1. Oktober 1999), hg. v. Andreas Henning/Gregor J. M. Weber, Emsdetten u. a.

Diebold, William J. (2000), Word and Image. An Introduction to Early Medieval Art, Boulder (CO).

Die Enzyklopädie (2008), Die Enzyklopädie des Isidor von Sevilla, übers. v. Lenelotte Möller, Wiesbaden.

Dünne, Jörg/Doetsch, Hermann / Lüdeke, Roger (Hgg.) (2004), Von Pilgerwegen, Schriftspuren und Blickpunkten. Raumpraktiken in medientheoretischer Perspektive, Würzburg.

Durliat, Marcel (1999), Romanisches Spanien, Darmstadt.

Eisenlohr, Erika (1994), „Monogramme und Invokationszeichen in iberischen und fränkischen Urkunden“, in: Signo 1, 35-50.

Español Bertran, Francesca (2005-2006), „El Castillo de Loarre y su portada románica“, in: Locus Amoenus 8, 7-18.

Etymologiarum (1911), Etymologiarum sive originum libri XX, hg. v. Wallace M. Lindsay, Oxford.

Favreau, Robert (1996), „Les inscriptions du tympan de la cathédrale de Jaca“, in: Comptes rendus des séances de l'Académie des Inscriptions et Belles-Lettres 140, 2, 535-560.

Frese, Tobias (2013), Aktual- und Realpräsenz. Das eucharistische Christusbild von der Spätantike bis ins Mittelalter (Neue Frankfurter Forschungen zur Kunst 13), Berlin.

Frese, Tobias (2014), ,,Denn der Buchstabe tötet‘ - Reflexionen zur Schriftpräsenz aus mediävistischer Perspektive“, in: Tobias Frese/Wilfried E. Keil/ Kristina Krüger (Hgg.), Verborgen, unsichtbar, unlesbar - zur Problematik restringierter Schriftpräsenz (Materiale Textkulturen 2), Berlin / Boston, 1-15.

Frese, Tobias / Keil, Wilfried E. (2015), „Schriftakte/Bildakte“, in: Thomas Meier/Michael R. Ott/ Rebecca Sauer (Hgg.), Materiale Textkulturen. Konzepte - Materialien - Praktiken (Materiale Textkulturen 1), Berlin / Boston, 633-638.

García García, Francisco de Asís (2011), „,HII TRES IVRE QVIDEM DOMINVS SVNT VNVS ET IDEM‘. El tímpano de Jaca y la escenificación de la ortodoxia“, in: Javier Martínez de Aguirre / Marta Poza Yagüe (Hgg.), Alfonso VI y el arte de su época, Madrid (Volumen extraordinario de Anales de Historia del Arte), 123-146.

García García, Francisco de Asís (2012), „Dogma, Ritual y Contienda. Arte y Frontera en el Reino de Aragón a finales del siglo XI“, in: Juan Martos Quesada / Marisa Bueno Sánchez (Hgg.), Fronteras en discusión. La Península Ibérica en el siglo XII, Madrid, 217-250.

Gier, Albert (1985), „Ein mehrdeutiges Tier: Der Löwe im französischen Mittelalter“, in: Martin Gosebruch (Hg.), Der Braunschweiger Burglöwe. Bericht über ein wissenschaftliches Symposion in Braunschweig vom 12.10. bis 15.10.1983 (Schriftenreihe der Kommission für Niedersächsische Bau- und Kunstgeschichte bei der Braunschweigischen Wissenschaftlichen Gesellschaft 2), Göttingen, 189-200.

Giersiepen, Helga/ Kottje Raymund (Hgg.) (1995), Inschriften bis 1300. Probleme und Aufgaben ihrer Erforschung. Referate der Fachtagung für mittelalterliche und frühneuzeitliche Epigraphik, Wiesbaden.

Großmann, Ulrich G. (2005), Burgen in Europa, Regensburg.

Guitart Aparicio, Cristóbal (2004), El Castillo de Loarre, Léon. 
Jaspert, Nikolas (2014), „The True Cross of Jerusalem in the Latin West. Mediterranean Connections and Institutional Agency“, in: Bianca Kühnel/Galit Noga-Banai / Hanna Vorholt (Hgg.), Visual Constructs of Jerusalem, Turnhout, 207-221.

Jaspert, Nikolas (2015), ,Eleventh-century pilgrimage from Catalonia to Jerusalem. New Sources on the Foundations of the First Crusade“, in: Crusades, Bd.14, Aldershot, 1-47.

Kendall, Calvin B. (1996), „The Verse Inscription of the Tympanum of Jaca and the PAX Anagram“, in: Mediaevalia 19, 405-434.

Kendall, Calvin B. (1998), The Allegory of the Church. Romanesque Portals and Their Verse Inscriptions, Toronto.

Kingsley, Jennifer P. (2012), „VT CERNIS and the Materiality of Bernwardian Art“, in: Gerhard Lutz/ Angela Weyer (Hgg.), 1000 Jahre St. Michael in Hildesheim, Petersberg, 171-184.

Klotz, Heinrich (1976), „Formen der Anonymität und des Individualismus in der Kunst des Mittelalters und der Renaissance“, in: Gesta 15 (= Essays in Honor of Sumner McKnight Crosby, hg. v. Pamela Z. Blum), 302-312.

Leonardy, Heribert J./Kersten, Hendrik (2002), Burgen in Spanien. Eine Reise ins spanische Mittelalter, Darmstadt.

Mann, Janice (2009), Romanesque Architecture and its Sculptural Decoration in Christian Spain 1000-1120. Exploring Frontiers and Defining Identities, Toronto.

Matarredona Sala, Francisco (2003), Crismones trinitarios medievales. Un símbolo pétreo genuino de los reinos de Aragón y Navarra. Épocas románica y protogótica (siglos XI-XIII), Zaragoza.

Matarredona Sala, Francisco (2009), Crismones romanicos trinitarios en la comarca de las cinco villas, Zaragoza.

Ocón Alonso, Dulce (2004), El tímpano de Jaca. Nuevas perspectivas, in: Ángela Franco Mata (Hg.), Patrimonio artístico de Galicia y otros estudios, Santiago de Compostela, 217-227.

Ostermann, Judith (2017), „Von der Wanderung eines Kaiserbildes - Konstantin in Hispania und Reconquista“, in: Horst Bredekamp/Stefan Trinks (Hgg.), Transformatio et continuatio. Forms of Change and Constancy of Antiquity in the Iberian Peninsula 500-1500 (Transformationen der Antike 43), Berlin / Boston, 245-290.

Poza Yagüe, Marta (2009), „Fortaleza militar y refugio de fe: proceso constructivo y relaciones estilísticas del conjunto de Loarre“, in: Pedro Luis Huerta (Hg.), Siete maravillas del románico español, Aguilar de Campoo, 51-81.

Power and Protection (2016), Power and Protection. Islamic Art and the Supernatural (Katalog zur Ausstellung des Ashmolean Museum in Oxford, 20. Oktober 2016 - 15. Januar 2017), hg. v. Francesca Leoni, Oxford.

Schmidt, Heinrich / Schmidt, Margarethe (1984), Die vergessene Bildersprache christlicher Kunst. Ein Führer zum Verständnis der Tier-, Engel- und Mariensymbolik, München.

Schreiner, Klaus (2003), „Göttliche Schreib-Kunst. Eigenhändige Aufzeichnungen Gottes, Jesu und Maria. Schriftlichkeit in heilsgeschichtlichen Kontexten“, in: Frühmittelalterliche Studien 36, 95-132.

Schweinfurth, Philipp (1943), Die byzantinische Form. Ihr Wesen und ihre Wirkung, Berlin.

Seehausen, Frank (2017), „Translationen der Antike. Römische Triumphalbogenmotive nordspanischer Kirchenportale am Jakobsweg“, in: Horst Bredekamp/Stefan Trinks (Hgg.), Transformatio et continuatio. Forms of Change and Constancy of Antiquity in the Iberian Peninsula 500-1500 (Transformationen der Antike 43), Berlin / Boston, 213-244.

Signos (1993), Signos. Arte y cultura en el Alto Aragón medieval (Katalog zur Ausstellung in Jaca, Museo Diocesano und Huesca, Sala de Exposiciones, 26. Juni - 26. September 1993), hg. v. Maria Carmen Lacarra Ducay / Carmen Morte García, Huesca.

Trinks, Stefan (2002), „Beinerne Bilder - Sechs Elfenbeinreliefs zwischen Zweifel und Glauben“, in: Herbert Beck/Hartmut Krohm (Hgg.), Ansichtssache. Das Bodemuseum Berlin im Liebieghaus Frankfurt. Europäische Bildhauerkunst von 800 bis 1800, Wolfratshausen, 19-37. 
Trinks, Stefan (2009), „Schlangenikonographie zwischen León und Jaca - eine Zeichenlehre des Bösen nach Isidor von Sevilla“, in: Achim Arbeiter/Bettina Marten / Christiane Kothe (Hgg.), Hispaniens Norden im 11. Jahrhundert. Christliche Kunst im Umbruch, Petersberg, 220-234. Trinks, Stefan (2010), ,,Zieh“ den alten Adam aus!' Anfänge und Grenzfälle einer vestimentären Symbolik im Jahrhundert des Investiturstreits“, in: Philipp Zitzlsperger (Hg.), Kleidung im Bild. Zur Ikonologie dargestellter Gewandung, Emsdetten / Berlin, 11-32.

Trinks, Stefan (2012), Antike und Avantgarde. Skulptur am Jakobsweg im elften Jahrhundert: Jaca León - Santiago, Berlin.

Trinks, Stefan (2013), „Der Künstler im Zeichen des Kreuzes. Artistische Selbstnennungen an der Grenze zur Selbstverherrlichung“, in: Nicole Hegener (Hg.), Künstler-Signaturen von der Antike bis zur Gegenwart, Petersberg, 100-115.

Werckmeister, Otto Karl (1972): „The Lintel Fragment Representing Eve From Saint-Lazare, Autun“, in: Journal of the Warburg and Courtauld Institutes 35, 1-30.

Whitehill, Walter Muir (1928), „An Inscription of 1095 at Loarre“, in: Speculum 3, 2, 254.

\section{Bildnachweise}

Abb. 1, 3, 6, 9a, 10-13: Stefan Trinks.

Abb. 2: Pedro de Palol, Spanien. Kunst des frühen Mittelalters vom Westgotenreich bis zum Ende der Romanik, München 1965, 73, Abb. 96.

Abb. 4: Francesca Español Bertran, „El Castillo de Loarre y su portada románica“, in: Locus Amoenus 8 (2005-2006), 9.

Abb. 5: Cristóbal Guitart Aparicio, El Castillo de Loarre, Léon 2004, 20.

Abb. 8: Zodiaque Aragón, Abb. 58.

Abb. 9b: Seibt, Werner/Zarnitz, Marie Luise (Hgg.), Das byzantinische Bleisiegel als Kunstwerk (Katalog zur Ausstellung im Museum für Byzantinische Kunst der Staatlichen Museen Berlin), Wien 1997, 71. 